\title{
Design of Trolox Compounds as Antioxidant and Their Analysis Using Quantitative Structure Activity Relationship
}

\author{
Hasmalina Nasution, Nur Enizan, Nurlaili, Jufrizal Syahri
}

Department of Chemistry, Muhammadiyah University of Riau,

Jl. KH. Ahmad Dahlan No.88, Kp. Melayu, Kec. Sukajadi, Kota Pekanbaru, Riau 28156, Indonesia *jsyahri@umri.ac.id

DOI: $10.29303 /$ aca.v3i2.40

\author{
Article info: \\ Received 19/07/2020 \\ Revised 10/10/2020 \\ Accepted 12/10/2020 \\ Available online 18/10/2020
}

\begin{abstract}
Abbreviations:
QSAR: Quantitative Structure Activity Relationship;

HOMO: the Highest Occupied

Molecular Orbitals energy:

LUMO: the Low Unoccupied

Molecular Orbitals energy
\end{abstract}

\begin{abstract}
Antioxidant compounds can inhibit the oxidation of lipids and other biomolecules. Antioxidants' role is crucial in neutralizing and destroying free radicals that can damage cells in the body. This research was carried out to design trolox derivate compounds as antioxidants using the QSAR method. The semi-empirical AM1(Austin Model 1)method was used to generate the QSAR model. The statistical analysis result using multiple linear regression methods revealed that antioxidant activity was influenced by the descriptors of $\mathrm{qC1}$, qC4, qO7, qC13, and qO18. The QSAR equation model obtained was $\log$ IC50 $=0.821+7.067(\mathrm{qC} 1)+2.585(\mathrm{qC} 4)+4.812(\mathrm{qO})-5.363$ (qC13) -0.887 (qO18) with the best predicted IC50 value was $4.699 \mu \mathrm{M}$.
\end{abstract}

Keywords: Antioxidants, QSAR, semi-empirical AM1, trolox

Citation:

\section{INTRODUCTION}

Antioxidant compounds can inhibit or slow down the oxidation of lipids and other biomolecules [1]. Antioxidants function to neutralize and destroy free radicals that can damage cells, lipids, proteins, and DNA in the body [2]. Cell damage can eventually lead to degenerative diseases such as cancer, heart disease, arthritis, cataracts, diabetes, and liver [3]. This degenerative disease is caused because antioxidants in the body are unable to neutralize the increase in the concentration of free radicals, so it is necessary to have antioxidants from outside the body (exogenous antioxidants) to neutralize them [4].

Trolox (6-hydroxy-2,5,7,8-tetramethyl chromane-2carboxylic acid) is one of the most widely known antioxidants and is a phenolic compound with high antioxidant potential. Trolox is usually used as an antioxidant platform in the synthesis process $[5,6]$. Apart from being an antioxidant, trolox is also reported to be active as a multi-target agent in the treatment of Alzheimer's disease, neuroprotective agent, anticancer [7,8,9], anti-inflammatory [10], hypothermia [11], protection of Gamma-ray irradiation [12], anti blinking and anti bleaching [13], inhibits apoptosis [14], antidiabetic [15], prevents osteoclastogenesis [16], reduces cortical nerve injury [17].

To get better antioxidant activity, the trolox compound design was performed using QSAR analysis. The QSAR method has been widely used in the design of new drug compounds [18]. In this research, a QSAR study was conducted to determine the active site responsible for antioxidant activity. The resulting QSAR equation can help determine what substituents must be added to get the best antioxidant activity.

\section{MATERIALS AND METHODS}

\section{Materials and Devices}

This research uses a laptop with the specifications used: Intel ${ }^{\circledR}$ Celeron $₫$ N4000 CPU @ $1.10 \mathrm{GHz}, 4.00$ GB Random Access Memory (RAM), Windows 10 64-bit Operating System. The software used is 
ChemDraw Ultra 12.0, Chem3D Pro 12, Gaussian, IBM SPSS 23.0 used for statistical analysis, and determining the QSAR equation.

This study's material was taken from the research of Yushkova et al. (2017) in the form of 14 troloxderived compounds and their antioxidant activity.

\section{Methods}

\section{Method determination}

One of the best compounds from the compound series (Table 1.) is optimized by using the AM1, PM3, and HF methods to obtain HNMR calculation data. ${ }^{1} \mathrm{HNMR}$ calculation data will be compared with experimental ${ }^{1} \mathrm{HNMR}$ data. The method that produces the smallest or closest value of PRESS (Predictive Residual Sum of Square) is the best method and is used as a method for the optimization of all compounds.

\section{Geometry optimization}

Fourteen trolox-derived compounds were structured in two dimensions using ChemDraw Ultra 12.0 software. Then, fourteen trolox-derived compounds were pre-optimized using Chem3D Pro 12.0 software.

\section{Modeling}

Fourteen trolox-derived compounds were divided into two data groups: training sets (to build models) and test sets (to validate models). The distribution of training sets and test sets is done randomly.

\section{QSAR model and data analysis}

Fourteen compounds in the preparation of the model that became the study material in this study were divided into two data groups: a training set and a test set. The distribution of training sets and test sets is done randomly. A number of compounds in the training set are analyzed using multiple linear regression with the backward method to obtain several models of the relationship between the $\mathrm{IC}_{50} \log$ with electronic and molecular descriptors. Of the several models produced, the model is chosen that meets the statistical parameters specified to be tested for validity such as $r^{2}$, PRESS, SEE, and $F_{\text {calculate }} / F_{\text {table }}$ with criteria $r^{2}>$ 0.64 [5], SEE <0.3 [19], Fcalculate / Ftable $\geq 1$ [20]. Models that fit the criteria are then validated using test data sets.

\section{Linear regression analysis}

Before analyzing the data, the $\mathrm{IC}_{50}$ value is changed to the $\mathrm{IC}_{50} \log$ value to narrow the range of data used. The determination of influential descriptors was calculated by compound activity based on linear regression analysis using the IBM SPSS 23.0 backward method on the separated data. Each electronic descriptor is designated as the independent variable and $p \mathrm{IC}_{50}$ as the dependent variable. Besides, this regression method estimates the value of the regression coefficient by applying the least square curve fitting method.

\section{Proposed compound design}

The best validation results model is used to predict the proposed compounds' activity value ( $\log \mathrm{IC}_{50}$ ). The proposed compounds are designed by replacing the substituents of trolox-derived compounds. Substitution of substituents is based on the relationship between substituent properties and compound activity. Compounds that have been designed, calculated molecular orbitals, and performed electronic descriptors calculations affect antioxidant activity. The IC50 value of the proposed antioxidant compound was calculated by entering the value of an influential electronic descriptor (included in the QSAR equation). The compound with the lowest IC $\mathrm{C}_{50} \mathrm{Log}$ value is stated as the bestproposed compound.

\section{RESULTS AND DISCUSSION}

The results of chemical shift calculations are best shown by the AM1 method with a correlation value $(r)=0.96$ and PRESS $=2.02$. The higher the $r$-value and the lower the PRESS value indicates that the results of the chemical shift calculation are getting closer to the experimental results. Based on these results, the process of calculating the molecular orbital series of trolox derivative compounds in this study was carried out using the semiempirical method AM1.

Table 1. Comparison of ${ }^{1} \mathrm{H}-\mathrm{NMR}$ shift value of experimental results and calculations using AM1, PM3, and $\mathrm{HF} / 3-21 \mathrm{G}$ methods.

\begin{tabular}{|c|c|c|c|c|}
\hline \multirow{2}{*}{$\begin{array}{c}\text { Atom } \\
\text { Number } \\
\text { H }\end{array}$} & \multirow{2}{*}{$\begin{array}{c}{ }^{1} \mathrm{H}-\mathrm{NMR} \\
\text { Experiment }\end{array}$} & \multicolumn{3}{|c|}{$\begin{array}{c}\text { 1H-NMR } \\
\text { Calculation }\end{array}$} \\
\hline & & AM1 & PM3 & $\begin{array}{r}\mathrm{HF} / 3 \\
21 \mathrm{G}\end{array}$ \\
\hline 23 & 2.03 & 2.40 & 1.90 & 1.13 \\
\hline 25 & 1.95 & 2.17 & 1.90 & 0.96 \\
\hline 27 & 1.56 & 1.72 & 0.55 & 1.73 \\
\hline 31 & 2.00 & 2.17 & 1.27 & 0.71 \\
\hline 34 & 2.30 & 3.10 & 2.24 & 1.80 \\
\hline 37 & 1.37 & 1.56 & 1.04 & 0.43 \\
\hline 40 & 2.73 & 3.41 & 3.60 & 5.50 \\
\hline 41 & 2.44 & 3.17 & 2.99 & 1.94 \\
\hline 43 & 3.49 & 3.83 & 3.52 & 3.01 \\
\hline \multicolumn{2}{|c|}{ Correlation (r) } & 0.96 & 0.90 & 0.67 \\
\hline \multicolumn{2}{|c|}{ PRESS } & 2.02 & 2.74 & 12.80 \\
\hline
\end{tabular}

\section{Calculation of descriptors}

The calculation of descriptors is an essential step in the QSAR study. Electronic descriptors used in this study are the net charge of atoms (q), the highest occupied molecular orbitals (HOMO) energy, and the low unoccupied molecular orbitals (LUMO) energy. 


\section{Preparation of the QSAR model}

A total of 14 antioxidant compounds from the trolox derivative used in this study were randomly divided into two data groups, namely the training set and test set. The training set compounds were analyzed statistically to produce the QSAR model, while the test set compounds were used to validate the resulting QSAR model. Before the linear regression analysis is performed, the $\mathrm{IC}_{50}$ value is converted to a logarithmic scale with the aim that the range of $\mathrm{IC}_{50}$ values between compounds does not differ greatly, and the distribution of $\mathrm{IC}_{50}$ values is getting better.

\section{Model analysis}

The training set compound was analyzed using the multiple linear regression (MLR) method, which aims to obtain the QSAR equation. Analysis using the MLR method was chosen because it involves more than one electronic descriptors. Based on the statistical analysis results with the MLR (backward) method, two QSAR equation models are generated, as shown in Table 3.

Table 2. Series of compounds and antioxidant activities used in the training set and test set.

\begin{tabular}{ccc}
\hline Compound & $\begin{array}{c}\mathrm{IC}_{50} \\
(\mu \mathrm{M})\end{array}$ & $\begin{array}{c}\text { Log } \mathrm{IC}_{50} \\
(\boldsymbol{\mu M})\end{array}$ \\
\hline${ }^{*} 2 \mathrm{a}$ & 62 & 1.792 \\
$2 \mathrm{~b}$ & 60 & 1.778 \\
$2 \mathrm{c}$ & 65 & 1.813 \\
$2 \mathrm{e}$ & 54 & 1.732 \\
$2 \mathrm{~g}$ & 76 & 1.881 \\
$2 \mathrm{~h}$ & 58 & 1.763 \\
${ }^{*} 2 \mathrm{i}$ & 66 & 1.819 \\
$2 \mathrm{j}$ & 55 & 1.740 \\
$2 \mathrm{k}$ & 68 & 1.832 \\
$2 \mathrm{l}$ & 65 & 1.813 \\
${ }^{2} 2 \mathrm{~m}$ & 63 & 1.799 \\
$2 \mathrm{n}$ & 63 & 1.799 \\
$2 \mathrm{o}$ & 61 & 1.785 \\
$2 \mathrm{q}$ & 57 & 1.756 \\
\hline
\end{tabular}

Table 3. QSAR equation model results of multiple linear regression analysis

\begin{tabular}{llllll}
\hline Model & Variable & $\mathbf{r}^{2}$ & SEE & $\mathbf{F}_{\text {cal }} / \mathbf{F}_{\text {tab }}$ & PRESS \\
\hline 1 & qO18, qC1, qC13, qC14, qC4, qO7 & 0.935 & 0.017 & 2.006 & $1.226 \times 10^{-3}$ \\
2 & qO18, qC1, qC13, qC4, qO7 & 0.883 & 0.021 & 1.567 & $2.222 \times 10^{-3}$ \\
\hline
\end{tabular}

Table 3. shows that the 2 QSAR models were produced to meet the established statistical parameters. The accuracy is shown by the five QSAR models in Table 4 . is very good. This can be seen from the SEE and PRESS values that are close to zero [16].

\section{Model validation}

To ensure models 1 and 2 are the best models, validation is done using a test data set. Model validation is performed on the test data set by calculating the value of the Predicted Residual Sum of Square (PRESS). PRESS data is obtained from the difference between the values of the antioxidant activity of experimental results with the test set compounds' prediction activity based on selected models. The value of PRESS shows how much error is generated by the model. The smaller the value of PRESS is, the model better. The PRESS value of the compound test set from the $\mathrm{IC}_{50}$ Log experimental results with all models' predicted results is shown in Table 4.

Table 4 shows that the best correlation value and the smallest PRESS is model 2, with a correlation value of 0.944 and PRESS 0.002. Thus, model 2 is the best QSAR model compared to other models. Model 2 involves descriptors that affect activities are qO18, qC1, qC13, qC4, and qO7. Efforts to further ensure that model 2 is the best QSAR model, then the $\mathrm{IC}_{50}$ Log plot was made as a result of the prediction of test set compounds in models 1 and 2.
Table 4. Differences in the PRESS Log IC50 experiments' values with the $\mathrm{IC}_{50} \mathrm{Log}$ predictions of the five models on the compound test set.

\begin{tabular}{|c|c|c|c|}
\hline \multirow{2}{*}{$\begin{array}{l}\text { Compound } \\
\text { Test Set }\end{array}$} & \multirow{2}{*}{$\begin{array}{c}\log \mathrm{IC}_{50} \\
\text { Experiment }\end{array}$} & \multicolumn{2}{|c|}{ Log $\mathrm{IC}_{50}$ Prediction } \\
\hline & & Model 1 & Model 2 \\
\hline $2 a$ & 1.792 & 1.708 & 1.800 \\
\hline $2 \mathrm{i}$ & 1.799 & 1.822 & 1.792 \\
\hline $2 \mathrm{~m}$ & 1.819 & 1.851 & 1.871 \\
\hline Correlation (r) & & 0.820 & 0.944 \\
\hline PRESS & & 0.008 & 0.002 \\
\hline
\end{tabular}

The value of $\mathrm{r}^{2}$ pred based on model 2 on the test set compound was very good at 0.8911 compared to the $\mathrm{r}^{2}$ pred value on model 1 , which was 0.6723 . This value indicates that model 2 can very well predict antioxidant activity in trolox-derived compounds. The QSAR equation from model 2 is:

$\log \mathrm{IC}_{50}=0.821+7.067(\mathrm{qC} 1)+2.585(\mathrm{qC} 4)+4.812$ $(\mathrm{qO} 7)-5.363(\mathrm{qC} 13)-0.887(\mathrm{qO} 18)$

The value of $\mathrm{r}^{2}=0.8911$ in the IC 50 Log experimental results and prediction results of the test data set using model 2 shows that the correlation between the independent variables with antioxidant activity is quite significant. This means that $89.1 \%$ of changes in antioxidant activity (Log $\mathrm{IC}_{50}$ ) of troloxderived compounds are caused by changes in the value of the independent variables and the $\mathrm{C} 1, \mathrm{C} 4$ net charge $\mathrm{O} 7, \mathrm{C} 13$, and $\mathrm{O} 18$ atoms. 


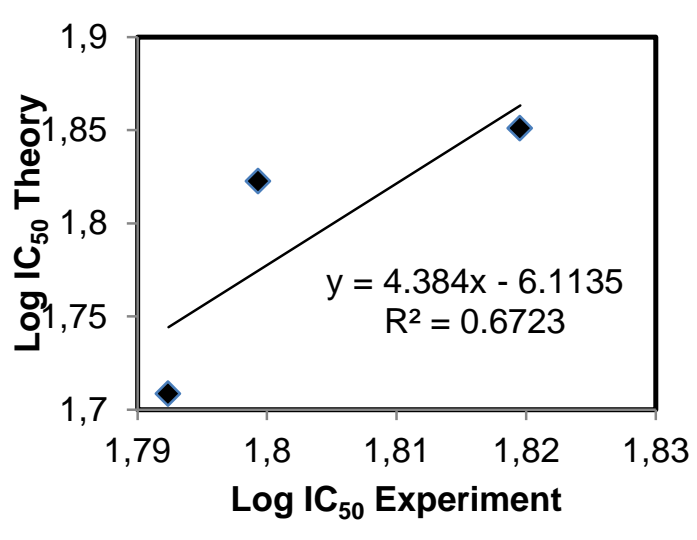

Figure 1. The plot of $\log \mathrm{IC}_{50}$ values from experimental results and prediction results of test set compounds using model 1

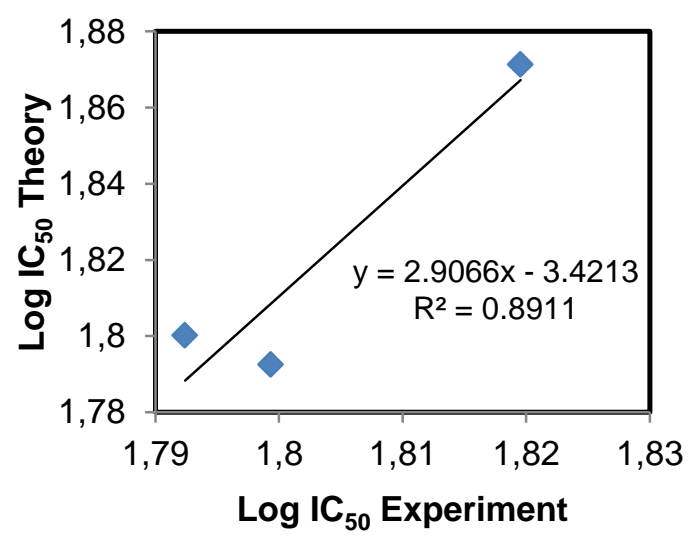

Figure 2. The plot of $\log \mathrm{IC}_{50}$ values from experimental results and prediction results of test set compounds using model 2

\section{Proposed antioxidant design}

The proposed antioxidant compounds in this study were designed by replacing the substituents in the trolox parent compound. It is expected that the compound designed to have antioxidant activity (IC50) is better than the previous trolox derivative compound. In the QSAR model 2 equation, it can be seen that the more negative the Log $\mathrm{IC}_{50}$ value is, the better the antioxidant activity. Therefore, to get a negative $\mathrm{IC}_{50}$ Log price, it is necessary to consider each influential descriptor's coefficients.

From equation 1 , it can be seen that to get the compounds with the best antioxidant activity, the atomic charge of $\mathrm{C} 1, \mathrm{C} 4$, and $\mathrm{O} 7$ must have a negative charge while the atomic charge of $\mathrm{C} 13$ and O18 must be positively charged. The design of the proposed compound can be done by adding a pulling group or electron booster. In the substitution of substituents, the electronic, hydrophobic, and steric properties of the atom or group to be included are considered. The electron withdrawal group is electrophilic so that the electron density of the atoms it binds becomes smaller. In contrast, the electron booster group is nucleophilic, which causes the electron density to increase.

In this study, as many as 10 antioxidant compounds have been proposed by trolox, as proposed in Table 5.

Table 5. Proposed antioxidant compounds

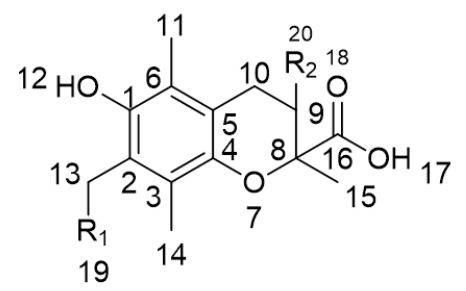

\begin{tabular}{lllll}
\hline Design & $\mathrm{R}_{1}$ & $\mathrm{R}_{2}$ & $\log \mathrm{IC}_{50}$ & $\mathrm{IC}_{50}(\mu \mathrm{M})$ \\
\hline 1 & & & & \\
2 & $\mathrm{OH}$ & $\mathrm{H}$ & 0.903 & 7.998 \\
3 & $\mathrm{OH}$ & $\mathrm{COOH}$ & 0.800 & 6.317 \\
4 & $\mathrm{~F}$ & $\mathrm{CH}_{3}$ & 0.768 & 5.856 \\
5 & $\mathrm{~F}$ & $\mathrm{C}_{3}\left(\mathrm{CH}_{3}\right)_{3}$ & 0.694 & 4.945 \\
6 & $\mathrm{~F}$ & $\left(\mathrm{CH}_{2}\right)_{2} \mathrm{CH}_{3}$ & 0.672 & 4.699 \\
7 & $\mathrm{~F}$ & $\mathrm{COOH}$ & 0.755 & 4.874 \\
8 & $\mathrm{OCH}_{3}$ & $\mathrm{CH}$ & 0.895 & 7.853 \\
9 & $\mathrm{OCH}_{3}$ & $\mathrm{H}$ & 0.929 & 8.487 \\
10 & $\mathrm{OCH}_{3}$ & $\mathrm{COOH}$ & 0.964 & 9.201 \\
\hline
\end{tabular}

It can be seen from Table 5 that design compounds $4,5,6$, and 7 are predicted to have the best estimated antioxidant activity with $\mathrm{IC}_{50}$ values $<6$ $\mu \mathrm{M}$. These four compounds have F substituents in C13, which are thought to cause their antioxidant activity to increase. Compared to other design compounds which do not have an F group substituent.

\section{CONCLUSION}

Based on the research that has been done, several conclusions can be drawn, namely:

1. AM1 method is the best optimization method used for the optimization of trolox derivative compounds.

2. The relationship of the structure of troloxderived compounds with antioxidant activity can be modeled using QSAR with the best QSAR equation: $\log \mathrm{IC}_{50}=0.821+$ $7.067(\mathrm{qC} 1)+2.585(\mathrm{qC} 4)+4.812(\mathrm{qO} 7)-$ $5.363(\mathrm{qC} 13)-0.887$ (qO18)

3. The influential descriptors for designing trolox derivatives are $\mathrm{qC} 1, \mathrm{qC} 2, \mathrm{qO} 7, \mathrm{qC} 13$, and qO18. 
4. The best QSAR model is used to design proposed compounds and predict the value of the antioxidant activity. The proposed compound with the best antioxidant activity is design compound 5 with an $\mathrm{IC}_{50}$ activity value of $4.699 \mu \mathrm{M}$.

\section{ACKNOWLEDGEMENT}

The authors thank the Ministry of Research and Technology of Higher Education for funding this research through the Basic Research Scheme (PD) in the fiscal year of 2019 with Contract Number 015/K10/KM/CONTRACT-RESEARCH-J/2019.

\section{REFERENCES}

[1] Wollinger, A., Perrin, E., Chahboun, J., Jeannot, V., Touraud, D., \& Kunz, W. (2016). Antioxidant Activity of Hydro Distillation Water Residues from Rosmarinus officinalis L. Leaves Determined by DPPH Assays. Comtes Rendus Chimie, 19: 754-765. DOI: 10.1016/j.crci.2015.12.014

[2] Wang, J., Li, S., Yang, T., \& Yang, J. (2014). Synthesis and Antioxidant Activities of Coenzyme Q Analogues. European Journal of Medicinal Chemistry 86: 710-713. DOI: 10.1016/j.ejmech.2014.09.042

[3] Venkatachalam, H., Nayak, Y., \& Jayashree, B. S. (2012). Evaluation of the Antioxidant Activity of Novel Synthetic Chalcones and Flavonols, International Journal of Chemical Engineering and $\begin{array}{lll}\text { Applications } & 3(3), & 216-219 . \\ \end{array}$ 10.7763/IJCEA.2012.V3.189

[4] Mohana, K. N. \& Kumar, C. B. P. (2013). Synthesis and Antioxidant Activity of 2-Amino-5methylthiazol Derivatives Containing 1,3,4Oxadiazole-2-thiol Moiety. International Scholarly Research Notices, 2013(3), 1-8. DOI: https://doi.org/10.1155/2013/620718

[5] Yushkova, Y. V., Chernyak E. I., Gatilov, Y. V., Vasil'ev, V. G., Morozov, S. V., \& Grigor'ev, I. A. (2017). Synthesis, Structure, Antioxidant Activity, and Water Solubility of Trolox Ion Conjugates. Saudi Pharmaceutical Journal 26(1), 84-92. DOI: 10.1016/j.jsps.2017.10.008

[6] Zakharova, O. D., Frolova, T. S., Yushkova, Y. V., Chernyak, E. I., Pokrovsky, A. G., Pokrovsky, M. A., Morozov, S. V., Sinitsina, O. I., Grigor'ev, I. A., \& Nevinsky, G. A. (2016). Antioxidant and Antitumor Activity of Trolox, Trolox Succinate, and $\alpha$ tocopheryl Succinate Conjugates with Nitroxides. European Journal of Medicinal Chemistry, 122, 127-137. DOI: 10.1016/j.ejmech.2016.05.051
[7] Lee, J. H., Kim, B., Jin, W. J., Kim, J. W., \& Kim, H. H. (2014). Trolox Inhibits Osteolytic Bone Metastasis of Breast Cancer Through Both PGE2-Dependent and Independent Mechanisms. Biochemical $\begin{array}{llll}\text { Pharmacology, } & \text { 91(1), 51-60. } & \text { DOI: }\end{array}$ 10.1016/j.bcp.2014.06.005

[8] Lee, J. H., Kim, H. N., Yang, D., Jung, K., Kim, H. M., Kim, H. H., and Ha, H. (2009). Trolox Prevents Osteoclastogenesis by Suppressing RANKL Expression and Signaling. The Journal of Biological Chemistry, 284(20), 13725-13734. DOI: 10.1074/jbc.m806941200

[9] Diaz, Z., Laurenzana, A., Mann, K. K., Bismar, T. A., Schipper, H. M., \& Miller, W. H. (2007). Trolox Enchances the Anti-lymphoma Effects of Arsenic Trioxide, While Protecting Against Liver Toxicity. Leukemia. 21, 2117-2127. DOI: https://doi.org/10.1038/sj.leu.2404891

[10] Moulin, C., Duflos, M., Baut, G.L., Grimaud, N., Renard, P., \& Caignard, D. H. (1998). Synthesis and Anti-inflamatory Activity of $\mathrm{N}$-(aza) arycarboxamides derived from Trolox. European Journal of Medicinal Chemistry, 33(4), 321-329. DOI: https://doi.org/10.1016/S0223-5234(98)80065-2

[11] Mcanulty, J. F \& Huang, X. Q. (1996). The Effect of Simple Hypothermic Preservation with Trolox and Ascorbate on Lipid Peroxidation in Dog Kidney. Cryobiology. 33(2), 217-225. DOI: 10.1006/cryo.1996.0022

[12] Sakashita, T., Doi, M., Yasuda, H., Fuma, S., \& Hader, D. P. (2002). Protective Gravitaxis in Euglena gracilis $\mathrm{Z}$ against Gamma-ray Irradiation by Trolox C. Journal of Radiation Research, 43, S257-S259. DOI: 10.1269/jrr.43.s257

[13] Cordes, T., Vogelsang, J., \& Tinnefeld, P. (2009). Mechanism of Trolox as Antiblinking and Antibleaching Reagent. Journal of American Chemical Society, 131(14), 5018-5019. DOI: https://doi.org/10.1021/ja809117z

[14] McClain, D.E., Kalinich, J.F., and Ramakrishnan, N. (1995). Trolox Inhibits Apoptosis in Irradiated MOLT-4 Lymphocytes, Faseb J. 9: 1345-1354.

[15] Ansari, N.H., Zhang, W., and Fulep, E. (1998). Prevention of Pericyte Loss by Trolox in Diabetic Rat Retina, J Toxicol Environ Health A. 54: 467-475.

[16] Lee, J. H., Kim, H. N., Yang, D., Jung, K., Kim, H. M., Kim, H. H., \& Ha, H. (2009). Trolox Prevents Osteoclastogenesis by Suppressing RANKL Expression and Signaling. The Journal of 
Biological Chemistry, 284(20) 13725-13734. doi: 10.1074/jbc.M806941200

[17] Chow, H. S., Lynch III, J. J., Rose, K., \& Choi, D. W. (1994). Trolox Attenuates Cortical Neuronal Injury Induced by Iron, Ultraviolet Light, Glucise Deprivation, or AMPA. Brain Research, 639(1), 102108. https://doi.org/10.1016/0006-8993(94)91769-8

[18] Syahri, J., Yuanita, E., Nurohmah, B. A., Wathon, M. H., Syafri, R., Armunanto, R., \& Purwono, B. (2017). Xanthone as Antimalarial: QSAR Analysis, Synthesis, Molecular Docking and In-Vitro Antimalarial Evaluation Oriental Journal of Chemistry, 33(1), 29-40. DOI: http://dx.doi.org/10/13005/ojc/330104
[19] Mishra, M., Mishra, V. K., Senger, P., Pathak, A. K., \& Kashaw, S. K. (2014). Exploring QSAR Studies on 4-substitued Quinazoline Derivatives as Antimalarial Compounds for the Development of Predictive Models. Medicinal Chemistry Research, 23(3), 1397-1405. DOI: 10.1007/s00044-013-0744-8

[20] Motta. L. F., and Almeida, W. P. (2011). Quantitative Structure Activity Relationships (QSAR) of A Series of Ketone Derivatives as Anti-Candida albicans. International Journal of Drug Discovery, 3(2), 100-117. 